\title{
Trends in Extreme Indices and Seasonal Analysis of Precipitation and Temperature in the Northwest Region of Rio Grande do Sul, Brazil
}

\author{
Tirzah Moreira de Melo, Jose Antônio S. Louzada, Olavo Correa Pedrollo \\ Institute of Hydraulic Researches (IPH), Federal University of Rio Grande do Sul (UFRGS), Porto Alegre, Brazil \\ Email: tirzahmelo@hotmail.com
}

Received 17 January 2015; accepted 15 May 2015; published 18 May 2015

Copyright (C) 2015 by authors and Scientific Research Publishing Inc.

This work is licensed under the Creative Commons Attribution International License (CC BY).

http://creativecommons.org/licenses/by/4.0/

(c) (i) Open Access

\begin{abstract}
Probably the most important environmental challenge of this century is to adapt to climate change and develop strategies to minimize its effects. This study aims to conduct an investigation to detect changes in temperature and precipitation in the northwest region of Rio Grande do Sul with the use of different general and regional circulation models (GCMs and RCMs, respectively). Seven distinct locations in the region were considered, for which there were ten different climate projections. Additionally, we investigated the frequency and intensity of extreme rainfall events using different extreme precipitation indices. These projections indicate an increase of mean annual temperature of almost $3^{\circ} \mathrm{C}$ till the end of the century, as well as an increase in annual precipitation. The seasonal analysis has demonstrated that the largest increases of temperature are projected for winter and early spring and do not coincide with the summer months of the main crop cultivation (soybean) in the region. Additionally, it is expected high amounts of rain during these same months. In general, trends in extreme precipitation indices were detected for the RCM projections in most of locations. It can also be concluded that it is possible that the spatial distribution of the impacts of climate change on agriculture will not be uniform.
\end{abstract}

\section{Keywords}

Climate Change, Climate Models, Extreme Precipitation Indices, Agriculture

\section{Introduction}

Probably the most important environmental challenge of this century is to adapt to climate change and develop

How to cite this paper: de Melo, T.M., Louzada, J.A.S. and Pedrollo, O.C. (2015) Trends in Extreme Indices and Seasonal Analysis of Precipitation and Temperature in the Northwest Region of Rio Grande do Sul, Brazil. American Journal of Climate Change, 4, 187-202. http://dx.doi.org/10.4236/ajcc.2015.43015 
strategies to minimize its effects. The major climate changes predicted for this century include an increase in average temperature, elevated $\mathrm{CO}_{2}$ concentration in the atmosphere, changes in rainfall spatial distribution, increase in evapotranspiration during summer and greater occurrence of extreme events such as windstorms, hail and heavy rainfall [1].

There is already a consensus that, even if all precautions to reduce emissions and carbon recovery are taken, an increase of $2^{\circ} \mathrm{C}$ in the average temperature of the Earth till the end of the XXI century (in a more optimistic scenario) seems inevitable [1] [2].

As a consequence, the global average surface temperatures registered during the last decade showed the highest increases, probably through the last millennium, being more expressive in the northern high latitudes. On the other hand, it is more difficult to characterize changes in precipitation regimes, as this is strongly influenced by regional climate phenomena such as El Niño and La Niña in South America. About this fact, the El Niño of 1998 was one of the most severe occurrences of the last century [3].

The meteorological variables exhibit both spatial and temporal variability and, allied to this fact, it is known that the climate models are still very inaccurate. It is possible that, even using different models to evaluate the uncertainties on climate projections, future climate conditions may not be covered by any of them.

These projections are generated by general or regional circulation models (GCMs and RCMs, respectively) as a result of future scenarios of climate forcings caused by the emission of greenhouse gases and aerosols [4]. Such models comprise partial differential equations systems based on physical laws of fluid motion and chemical substances [5], ranging from simple approaches of punctual energy balance to three-dimensional general circulation models, which attempt to model all complexities of the climate system of the Earth [3]. Since it is extremely difficult to properly simulate the climate, climate models often contain some simplifications, represented by different parameterizations. The use of different sets of parameters results in different output simulations or members, representing how sensitive to the parameters the model is. Thus, it is usual to considerer a “control” member associated with other disturbances such as a "high” member refers. The term "high" refers to a large disturbance on outputs associated to a certain set o parameters, whereas a "low" member indicates that the model is not that much sensitive, for example.

One can cite numerous papers on climate change which have used such models globally [6] [7]; some continental, for South America [8]-[10]; and for Brazil and/or some of its regions [11]-[18]. There is a consensus in most of the studies on climate change performed for South America that there will be an increase (decrease) in the frequency of warm (cold) nights and a higher frequency of days with heavy rainfall [14].

The study conducted for Brazil and presented by [19] included six GCMs and considered only the most pessimistic (A2) and the most optimistic (B2) scenarios. Climate scenarios are representations of future climate based on assumptions about changes in the composition of the atmosphere, as consequence of human activities. The projections for future climate in the country were compared in terms of anomalies with respect to the baseline scenario represented by the period of 1961-1990. The trends indicate an increase in temperature of up to $4^{\circ} \mathrm{C}$ in 2080, while larger differences are likely to occur from June to October, i.e., winters will become warmer compared to the summers. On the other hand, for changes in average daily precipitation in Brazil, there will be a decrease in the monthly amounts compared to the baseline period, but only few differences between future periods of short (2025s), medium (2055s) and long-term (2085s) are projected.

Their results also reveal that the south region of Brazil is likely to suffer with the largest increases in temperature especially during the spring months, while the projection for 2080 according to the $\mathrm{A} 2$ scenario is $5.5^{\circ} \mathrm{C}$ above the baseline average. Furthermore, it is estimated that the highest rainfalls for Brazil occur during the summer (40\%) and autumn (29\%) months. The precipitation anomalies observed in the South region showed a decrease throughout all the seasons.

It should be noted that the forecasts made for Brazil by [19] were obtained by the averaged projections of six GCMs and contradictory results on precipitation (increase rather than decrease) were found by other authors. For instance, [20] predicted an increase in annual precipitation for the entire south region of Brazil, while [21] found no significant changes or only a small increase up to the end of this century. These results serve to demonstrate that, among other aspects, the uncertainties of the models remain large and difficult to be assessed, justifying more researches, especially at regional scale with the use of RCMs.

It is known that $80 \%$ of the cultivated areas in the world are non-irrigated [20]. Thus, agricultural productivity becomes one of the most vulnerable sectors in developing countries, such as Brazil. In this context, Brazil is responsible for $27 \%$ of global soybean production [22], and the State of Rio Grande do Sul (RS) is the third largest 
producer in this country. Yet, the north and northwest regions are the largest producers of soybean in this state, becoming evident that the biggest challenge faced by agriculture over this century will be to deal with possible climate changes.

The main agronomic effects of climate change are related to the respiratory cycle of the plant, effects of changes in temperature and precipitation and rising sea level with a consequent reduction of cultivated areas due to an increase in soil salinity [23]. Another expected consequence of this century is that the elevated temperatures will cause a delay in the sub-periods of crop sowing and flowering, as evidenced by some authors for various crops in future scenarios [23]-[25].

In general, with respect to precipitation, it is expected that the rainy season will become wetter, while dry seasons will be even drier. In locations where there is an increase in water deficit for agriculture during the dry months, irrigation will require larger quantities of water, intensifying conflicts over its use [26]. It is known that continuous periods of time without precipitation lasting for more than 10 days during the rainy seasons negatively affect agricultural productivity [22].

It is possible that the soybean cultivation in south Brazil becomes increasingly difficult. The occurrence of heavy precipitation and strong winds may limit the use of machinery in some agricultural areas [27], besides the fact that hailstorms can destroy crops almost instantly. It is therefore extremely important to determine the frequency and intensity of extreme events, especially on precipitation, and which are their preferred locations of occurrence.

As mentioned by [8], the development of climate change scenarios at a regional scale can reveal pronounced variability, which may suggest a geographic distribution of impacts. In their studies, an increase of approximately $3{ }^{\circ} \mathrm{C}-4^{\circ} \mathrm{C}$ for the south region of Brazil is expected, and for this region, most of the models of the Intergovernmental Panel on Climate Change (IPCC) fourth Special Report agree to an increase in precipitation under a warmer climate.

Thus, given the agronomic importance of the State of Rio Grande do Sul in the Brazilian economy and the lack of studies on climate change specifically for the most productive region of this State, the present study aims to conduct an investigation to detect changes in temperature and precipitation in the northwest region of this state with the use of different GCMs and RCMs climate models projections.

\section{Materials and Methods}

\subsection{Study Area}

The study area comprises the northwest region of the state of Rio Grande do Sul (Figure 1). The geographical location of this state inserts it under the influence of atmospheric systems such as cold fronts and mesoscale convective systems, which may cause natural disaster and severe extreme events. In addition, the climatic phenomena El Niño and La Niña also determine the occurrence of floods and droughts in southern Brazil [28].

A recent study presented by [28] and representative of the 2003-2009 period showed that $70 \%$ of drought events recorded in the Rio Grande do Sul correspond to the northern half of the State. Moreover, higher frequency of dry events is registered during the summer months, so that crop yield during this period decreases because the crop cultivation period coincides with the most common dry months, from November to March [29].

The land use in the northwest region is essentially agricultural and, in most of the cases, crops are nonirrigated. In addition, this region is the largest soybean producer in the state, strongly contributing to its economic development. These reasons justify the choice of this region to analyze the vulnerability of this area under a changing climate.

\subsection{Meteorological Data}

Points in Figure 1 indicate the seven locations for which there are climate projections of the meteorological variables in the region. These projections include precipitation and temperature for the baseline period (19611990), near term (2011-2040), midterm (2041-2070) and far term (2071-2100). Future periods will be represented in this work by the central year on each (2025s, 2055s and 2085s). The information for each location is shown in Table 1.

Ten different projections for the A1B greenhouse gas emission scenario were considered at each location: five GCMs and five projections derived from the ETA regional climate model. The A1B scenario belongs to the 


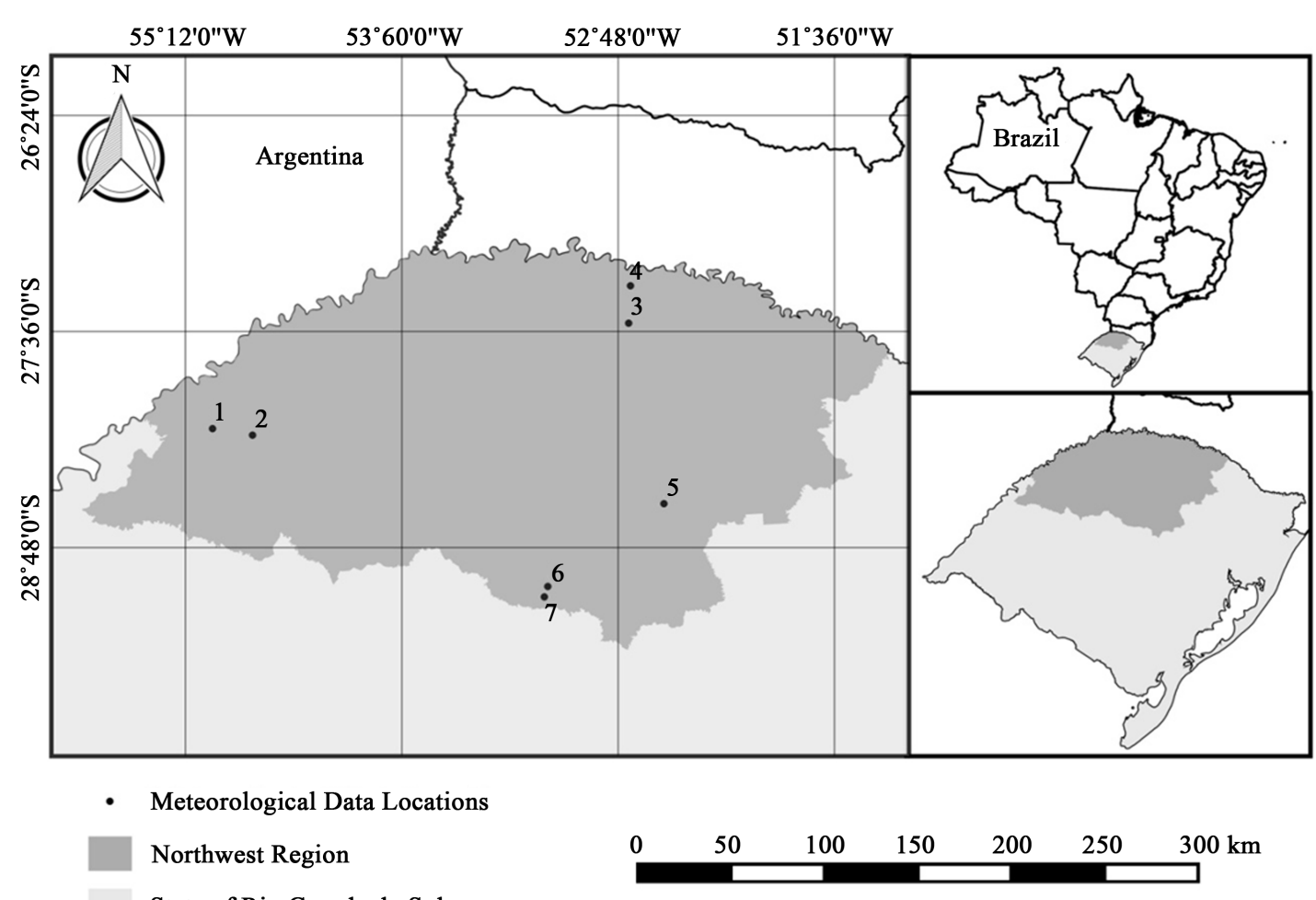

State of Rio Grande do Sul

Figure 1. Study area location.

Table 1. Meteorological data locations in the northwest region of Rio Grande do Sul.

\begin{tabular}{cccc}
\hline Location & Latitude $\left({ }^{\circ}\right)$ & Longitude $\left(^{\circ}\right)$ & Altitude (m) \\
\hline 1 & -28.14 & 55.05 & 123 \\
2 & -28.18 & 54.83 & 590 \\
3 & -27.55 & 52.74 & 275 \\
4 & -27.35 & 52.73 & 470 \\
5 & -28.56 & 52.55 & 323 \\
7 & -29.02 & 53.19 & 283 \\
\hline
\end{tabular}

family of climate scenarios A1, which suggests a future world of very rapid economic growth, global population that peaks mid-century and declines thereafter, and rapid introduction of new and more efficient technologies. The A1B scenario refers to a balance across fossil-intensive e nonfossil energy sources [30].

Global models description is shown in Table 2. The ETA model is descendant of the HIBU model (Hydrometeorological Institute and Belgrade University), previously developed by [31]. It is a regional climate model that couples the HadCM3 general circulation model as lateral boundary condition for mesoscale simulations. A more detailed description of this method can be found in [32]. The coupling of this global model considers a set of regional members (CTRL, LOW, MID and HIGH), which represent the climate sensitivity. The horizontal resolutions of the ETA model applied in this study were 20 and $40 \mathrm{~km}$, then providing five projections: ETA 20-CTRL, ETA 40-CTRL, ETA 40-LOW, ETA 40-MID, ETA-40 HIGH. Thus, for each of the 7 locations shown in Table 1, there are 10 sets of meteorological data derived from these different models. Additionally, only the member CTRL of all GCMs was applied. 
Table 2. General circulation models applied in this study.

\begin{tabular}{ccc}
\hline Model & Abbreviation $^{*}$ & Modeling group \\
\hline CCSM3, 2005 & NCCCSM & National Center for Atmospheric Research, USA \\
ECHAM5/MPI-OM, 2005 & MPEH5 & Max Planck Institute for Meteorology, Germany \\
GFDL-CM2.1, 2005 & GFCM21 & U.S Dept. of Commerce/NOAAA/Geophysical Fluid Dynamics Laboratory, USA \\
MRI-CGCM2.3.2, 2003 & MRCGCM & National Center for Atmospheric Research, USA \\
UKMO-HadCM3, 1997 & HADCM3 & Hadley Centre for Climate Prediction and Research/Met Office, UK \\
\hline
\end{tabular}

*Abbreviation adopt in this study. Adapted from [33].

Daily meteorological data refer to the mean temperature $\left(\mathrm{T},{ }^{\circ} \mathrm{C}\right)$ and precipitation $(\mathrm{P}, \mathrm{mm})$. As agriculture in the northwest region is moved primarily by soybean cultivation, it is necessary to determine whether changes in precipitation and temperature may occur during the months in which soybeans are cultivated. Therefore, we first carried out a monthly analysis of $\mathrm{T}$ and $\mathrm{P}$ data in order to investigate this point. In a second moment, we analyzed the occurrence of extreme rainfall events by the use of climate extreme indices (Table 3). This analysis could not be performed for the temperature, since only mean temperature data were available for the study area.

In Table 3, a wet day occurs when the daily rainfall rate is greater or equal to $1 \mathrm{~mm}$, and a dry day is when this rate is lower than $1 \mathrm{~mm}$. The same climate extreme indices (or some of them) were recently applied by other authors such as [13] and [14]. These indices will be of great importance, since they help detect the occurrence of extreme events related to precipitation. We are also interested in analyzing spatial distribution of these extreme events, considering seven different locations in the northwest region.

In order to detect trends in annual indices, the Mann-Kendall test [34] [35] was performed. It consists of a non-parametric test for assessing if there is a monotonic upward or downward trend of the variable of interest over time. Thus, it can be seen as a nonparametric test for zero slope of the linear regression of time-ordered data versus time [36]. The test was conducted at a $5 \%$ significance level.

\section{Results and Discussions}

\subsection{Annual Analysis of Temperature and Precipitation}

A brief analysis of annual meteorological data is presented in Table 4 and Table 5 . Table 4 provides the average annual temperature and the anomalies for all different locations in the study area. The anomaly refers to the difference between a future time slice and the baseline period. It is clear that the projections indicate that the temperature will increase in all locations, when compared to the baseline period (1961-1990). The largest anomalies were predicted for the end of the century, and a temperature diminution in the short term (2025s) is expected only in location 6 . Since some locations are close to each other, similar projections were found probably because they belong to neighbor resolution cells of the climate model. They were maintained in the study because different precipitation projections were provided by the models even for these locations.

The smallest anomalies were found for locations 4, 5 and 6, situated in the north, central and south portion of the region, respectively. Analyzing the long term period, we can note mean annual temperatures expected to be from $20.6^{\circ} \mathrm{C}$ to $22.7^{\circ} \mathrm{C}$, which may suggest a spatial distribution of the changes of temperature and that there may be an increase of almost $3^{\circ} \mathrm{C}$, in average, till the end of this century. Similar result were found by [8] for the Southern Brazil for A2 scenario. They found that the warming is projected by about $3^{\circ} \mathrm{C}-4^{\circ} \mathrm{C}$ given by regional climate models.

Analyzing the information presented in Table 5, one may observe that, as well as for temperature, it is expected an increase in the annual amount of rainfall, and it is more expressive for locations 2, 3, 4 and 5 . Again, only in location 6 , the models projected a reduction in precipitation in the near term. Indeed, for this location, the smallest anomalies were found, suggesting that probably it will not be affected by climate changes, or only small climate disturbances (not significant) might occur. The worst scenarios were projected for the same locations abovementioned, situated in higher altitudes. Increase in precipitation for Southern Brazil was also found by [8]. This is probably due to an increase in dry days, whereas the consecutive wet days are unchangeable (see Section 3.3). 
Table 3. Climate extreme indices related to precipitation of climate projections for the northwest region [14].

\begin{tabular}{l} 
Extreme index \\
$\begin{array}{l}\text { PRCPTOT } \\
\text { RX1 day } \\
\text { RX5 day } \\
\text { R30 } \\
\text { R95p } \\
\text { R99p } \\
\text { Annual total precipitation from wet days (mm) } \\
\text { Annual maximum 1-day precipitation (mm) } \\
\text { CWD }\end{array} \quad$ Annual total precipitation on the days when the daily rainfall rate is greater than 95th percentile (mm) \\
\hline
\end{tabular}

Table 4. Mean annual temperature and anomalies for each location in the northwest region of RS. The values correspond to the average of all ten projections (five global and five regional projections).

\begin{tabular}{|c|c|c|c|c|c|c|c|c|}
\hline \multirow{2}{*}{ Variable } & \multirow{2}{*}{ Period } & \multicolumn{7}{|c|}{ Location } \\
\hline & & 1 & 2 & 3 & 4 & 5 & 6 & 7 \\
\hline \multirow{4}{*}{$\begin{array}{c}\text { Mean } \\
\text { temperature } \\
\left({ }^{\circ} \mathrm{C}\right)\end{array}$} & Baseline & 19.73 & 19.74 & 17.65 & 18.73 & 18.51 & 20.01 & 18.51 \\
\hline & $2025 s$ & 20.86 & 20.91 & 18.82 & 18.93 & 18.80 & 19.67 & 19.65 \\
\hline & $2055 s$ & 21.83 & 21.92 & 19.81 & 19.93 & 19.79 & 20.67 & 20.64 \\
\hline & $2085 s$ & 22.57 & 22.69 & 20.59 & 20.69 & 20.63 & 21.52 & 21.47 \\
\hline \multirow{3}{*}{$\begin{array}{l}\text { Temperature } \\
\text { anomaly } \\
\left({ }^{\circ} \mathrm{C}\right)\end{array}$} & $2025 s$ & 1.13 & 1.17 & 1.17 & 0.20 & 0.29 & -0.34 & 1.14 \\
\hline & $2055 s$ & 2.10 & 2.18 & 2.16 & 1.20 & 1.28 & 0.66 & 2.13 \\
\hline & $2085 \mathrm{~s}$ & 2.84 & 2.95 & 2.94 & 1.96 & 2.12 & 1.51 & 2.96 \\
\hline
\end{tabular}

Table 5. Mean annual precipitation and anomalies for each location in the northwest region of RS. The values correspond to the average of all ten projections (five global and five regional projections).

\begin{tabular}{|c|c|c|c|c|c|c|c|c|}
\hline \multirow{2}{*}{ Variable } & \multirow{2}{*}{ Period } & \multicolumn{7}{|c|}{ Location } \\
\hline & & 1 & 2 & 3 & 4 & 5 & 6 & 7 \\
\hline \multirow{4}{*}{$\begin{array}{l}\text { Annual } \\
\text { Precipitation } \\
\text { (mm) }\end{array}$} & Baseline & 1728.23 & 1690.93 & 1785.34 & 1848.29 & 1651.65 & 1775.15 & 1595.05 \\
\hline & $2025 s$ & 1790.24 & 1816.71 & 1925.87 & 1998.27 & 1812.27 & 1770.04 & 1743.03 \\
\hline & $2055 s$ & 1873.20 & 1911.07 & 2061.18 & 2137.57 & 1938.98 & 1875.70 & 1846.75 \\
\hline & $2085 s$ & 1951.71 & 2013.06 & 2153.65 & 2228.96 & 2002.79 & 1943.48 & 1917.72 \\
\hline \multirow{3}{*}{$\begin{array}{c}\text { Annual } \\
\text { Precipitation } \\
\text { Anomaly } \\
(\mathrm{mm})\end{array}$} & $2025 s$ & 62.01 & 125.78 & 140.53 & 149.98 & 160.62 & -5.11 & 147.98 \\
\hline & $2055 s$ & 144.97 & 220.14 & 275.84 & 289.28 & 287.33 & 100.55 & 251.70 \\
\hline & $2085 s$ & 223.48 & 322.13 & 368.31 & 380.67 & 351.14 & 168.33 & 322.67 \\
\hline
\end{tabular}

Based on the data presented in these tables, we may conclude, a priori, that it could be expected positive impacts of these future scenarios. However, these values refer to the averaged annual temperature and precipitation for all models and they show nothing about the seasonal cycles of these variables. It is possible that higher amounts of precipitation are concentrated in months which are not interesting for agriculture in the northwest region of Rio Grande do Sul. Thus, to reasonably identify climate changes that might have impacts on agriculture, it is crucial to understand how these changes are distributed throughout the year. It is also important to 
point out that, in this study, we are not interested to evaluate the impacts on agriculture themselves, but only to detect whether they are expected to occur or not. How intense or frequent they are probably to be is out of the scope of this study. So, the analysis presented here is an attempt to identify climate changes in the region, based only on the temperature and precipitations projections.

\subsection{Seasonal Analysis of Temperature and Precipitation}

An initial analysis of temperature and precipitation projections was performed by taking the average of the monthly values of these variables given by all models in all locations and then calculating the anomalies compared to the baseline period (1961-1990) (Figure 2). The anomalies refer to the differences between each future period of 30 years and the baseline period, also represented by a series of 30 years of data.

It should be noted that the largest increases of temperature are projected for winter and early spring, from June to October. Additionally, the seasonal variability is similar for all future time slices. The average annual anomalies for $2025 \mathrm{~s}, 2055 \mathrm{~s}$ and $2085 \mathrm{~s}$ are $1.2^{\circ} \mathrm{C}, 2.1^{\circ} \mathrm{C}$ and $2.9^{\circ} \mathrm{C}$, respectively. The months with higher temperature anomalies are May and October (2025s), and August and September (2055s and 2085s). These months do not coincide with the summer months of the main crop cultivation (soybean) in the region, which is practiced from November to March. Indeed, these are the months when minor anomalies were obtained. However, it is projected that such anomalies are in the range of $1.0^{\circ} \mathrm{C}$ to $2.9^{\circ} \mathrm{C}$, which may not be neglected, especially at the end of the century.

The lowest mean anomalies provided for precipitation are expected during the winter months. For August, a reduction in precipitation of nearly $10 \mathrm{~mm}$ for the periods of 2025s and 2055s is expected, but any change for 2085s. For the remaining months of the year, all the anomalies are positive, i.e., increase in precipitation. This increase is more significant from April to May and from October to December. These results are coherent with those presented by [8], who also found an increase in precipitation for fall months and a reduction during the winter at the end of the century. The largest increases in precipitation coincide with winter crops (wheat and oats, sown in May) and the sowing period of the summer crop (soybean, sown in November). Thus, one may conclude that it is expected that the impacts will be positive with respect to precipitation. Furthermore, this increase in precipitation during the months of the summer crop also coincides to minor increases in temperature during this period.

However, higher amounts of precipitation does not necessarily indicate a positive impact, because higher amounts of rain concentrated in short periods of time can be associated to a greater occurrence of extreme events such as heavy rains and floods. If this is the case, then it is possible that the period of sowing of the summer crop (more important economically) is more strongly affected by climate change (discussed in the next section).

In order to evaluate the differences given by each climate model for each location, Table 6 presents the results of monthly temperature projections, divided into: averaged for general circulation models (AVG) and averaged for regional climate model projections (AVR). That is, each value in this table is the average of five projections of the ETA RCM or five projections of the GCMs. In the case of precipitation, it was decided to make a representation by graphs (Figures 3(a)-(g)), since the extent of the differences are larger and more noticeable than for temperature.
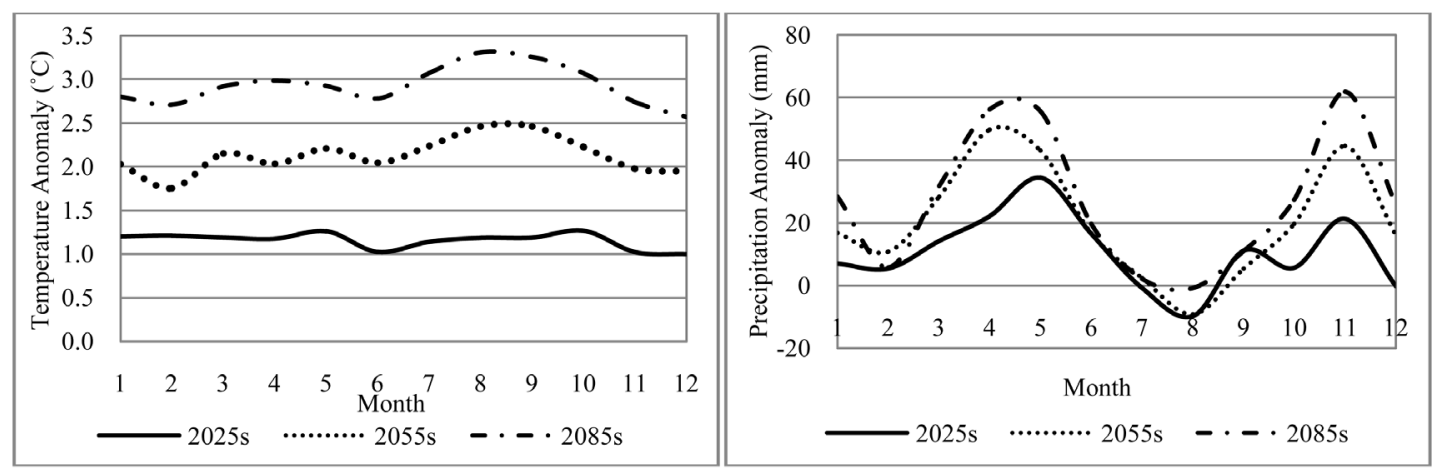

Figure 2. Seasonal cycles of temperature and annual precipitation anomalies. The curves correspond to the variable averaged for all climate projections and locations. 

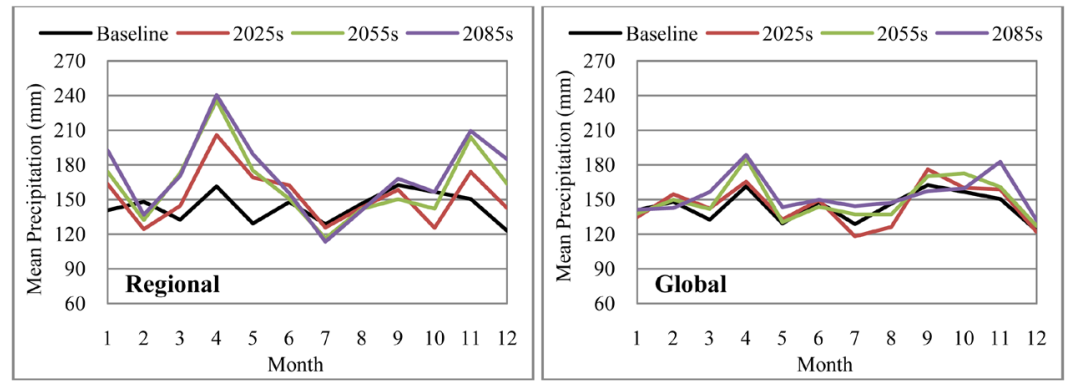

(a)
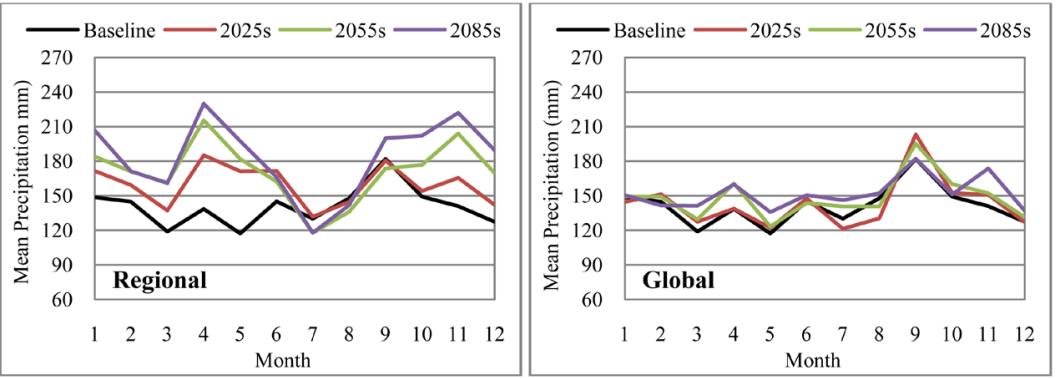

(b)
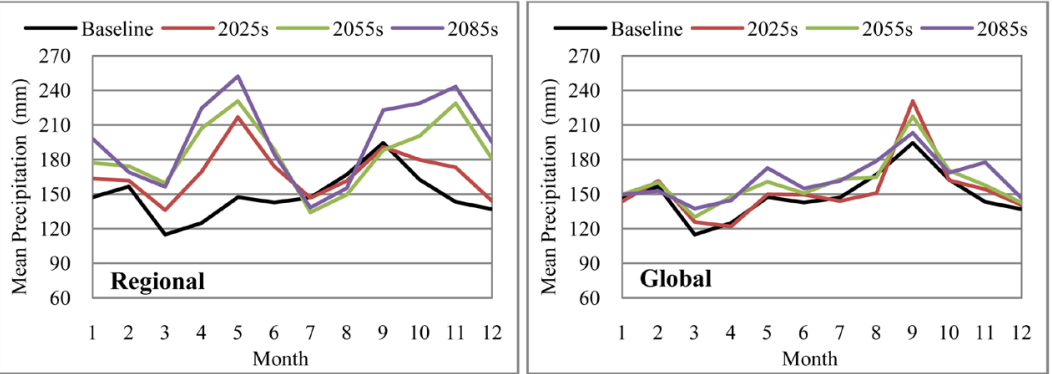

(c)
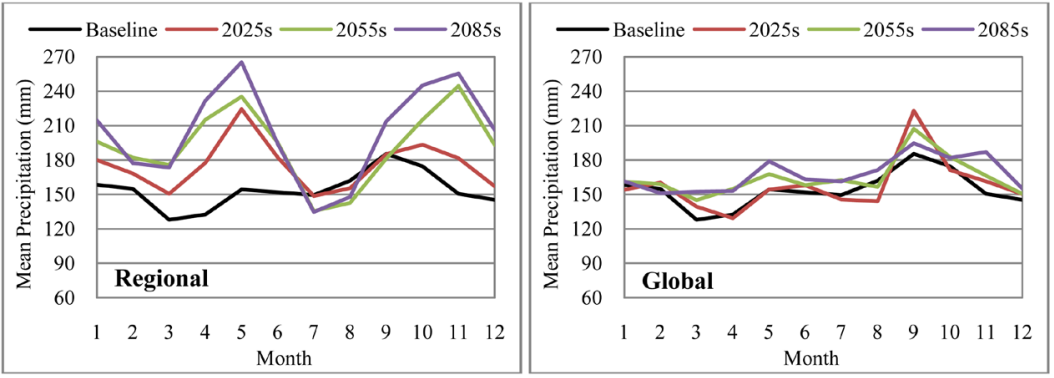

(d)
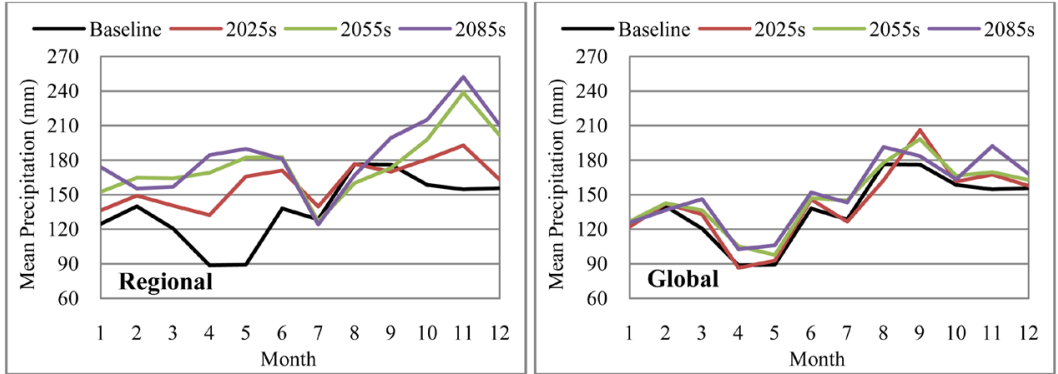

(e) 

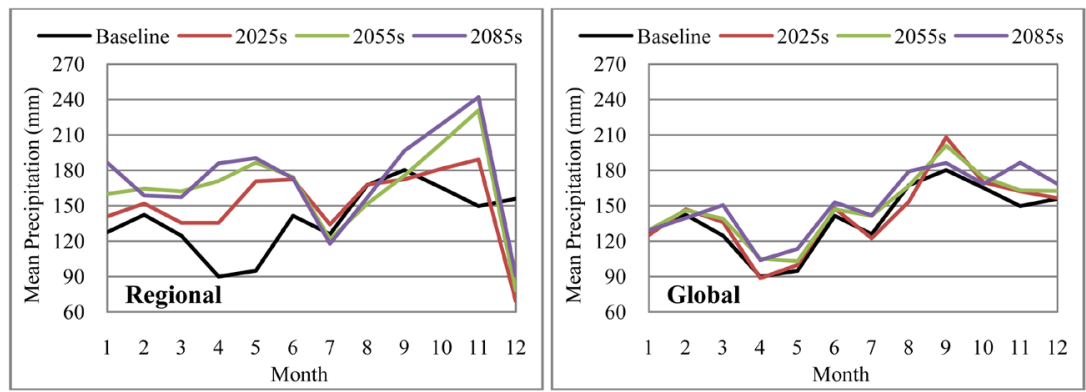

(f)
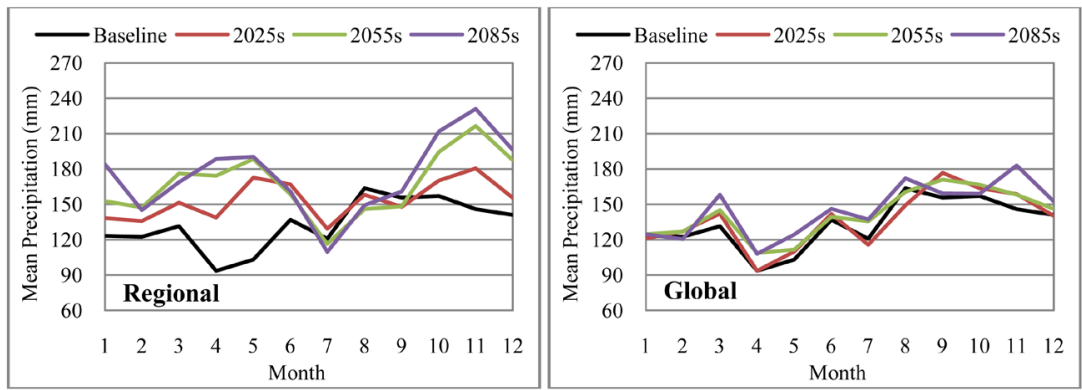

(g)

Figure 3. Seasonal cycles of monthly mean precipitation (mm/day) for locations 1 to 7 in (a) to (g), respectively. Black line is the annual cycle for the baseline period (1961-1990) and the color lines are the projected cycles for future time slices (2011-2040, 2041-2070 and 20712100). The graphics at left correspond to the averaged projections provided by the five RCM projections, and the graphics at right refer to the averaged five GCMs.

Table 6. Average monthly temperature projected by different climate models in all locations.

\begin{tabular}{|c|c|c|c|c|c|c|c|c|c|c|c|c|c|c|c|}
\hline \multirow{2}{*}{ Month } & \multirow{2}{*}{ Period } & \multicolumn{2}{|c|}{ Location 1} & \multicolumn{2}{|c|}{ Location 2} & \multicolumn{2}{|c|}{ Location 3} & \multicolumn{2}{|c|}{ Location 4} & \multicolumn{2}{|c|}{ Location 5} & \multicolumn{2}{|c|}{ Location 6} & \multicolumn{2}{|c|}{ Location 7} \\
\hline & & $\mathrm{AVG}^{\mathrm{a}}$ & $\mathrm{AVR}^{\mathrm{b}}$ & AVG & AVR & AVG & AVR & AVG & AVR & AVG & AVR & AVG & AVR & AVG & AVR \\
\hline \multirow{4}{*}{ Jan } & Baseline & \multicolumn{2}{|c|}{24.9} & \multicolumn{2}{|c|}{24.9} & \multicolumn{2}{|c|}{22.1} & \multicolumn{2}{|c|}{22.2} & \multicolumn{2}{|c|}{22.1} & \multicolumn{2}{|c|}{23.3} & \multicolumn{2}{|c|}{23.3} \\
\hline & $2025 s$ & 26.1 & 26.1 & 26.0 & 26.3 & 23.1 & 23.4 & 23.1 & 23.6 & 23.1 & 23.4 & 24.4 & 24.7 & 24.4 & 24.6 \\
\hline & $2055 s$ & 27.1 & 26.7 & 27.0 & 27.0 & 24.1 & 24.2 & 24.1 & 24.4 & 24.0 & 24.2 & 25.3 & 25.4 & 25.3 & 25.3 \\
\hline & $2085 s$ & 27.8 & 27.4 & 27.6 & 27.8 & 24.7 & 25.0 & 24.7 & 25.1 & 24.7 & 25.2 & 25.9 & 26.5 & 26.0 & 26.4 \\
\hline \multirow{4}{*}{ Feb } & Baseline & \multicolumn{2}{|c|}{24.4} & \multicolumn{2}{|c|}{24.4} & \multicolumn{2}{|c|}{22.0} & \multicolumn{2}{|c|}{22.2} & \multicolumn{2}{|c|}{22.0} & \multicolumn{2}{|c|}{23.0} & \multicolumn{2}{|c|}{23.0} \\
\hline & $2025 s$ & 26.2 & 26.3 & 25.3 & 25.8 & 22.9 & 23.4 & 22.9 & 23.6 & 22.8 & 23.4 & 23.8 & 24.4 & 23.9 & 24.4 \\
\hline & $2055 s$ & 25.3 & 25.6 & 26.1 & 26.6 & 23.6 & 24.1 & 23.6 & 24.3 & 23.6 & 24.2 & 24.6 & 25.2 & 24.6 & 25.2 \\
\hline & $2085 s$ & 26.2 & 26.2 & 27.0 & 27.6 & 24.5 & 25.1 & 24.5 & 25.3 & 24.5 & 25.4 & 25.5 & 26.5 & 25.5 & 26.3 \\
\hline \multirow{4}{*}{ Mar } & Baseline & \multicolumn{2}{|c|}{22.6} & \multicolumn{2}{|c|}{22.6} & \multicolumn{2}{|c|}{20.5} & \multicolumn{2}{|c|}{20.7} & \multicolumn{2}{|c|}{20.5} & \multicolumn{2}{|c|}{21.4} & & \\
\hline & $2025 s$ & 23.7 & 23.8 & 23.7 & 24.0 & 21.6 & 21.8 & 21.6 & 22.0 & 21.5 & 21.9 & 22.4 & 22.8 & 22.5 & 22.8 \\
\hline & $2055 s$ & 24.7 & 24.7 & 24.6 & 25.0 & 22.5 & 22.8 & 22.5 & 23.0 & 22.5 & 22.9 & 23.4 & 23.8 & 23.4 & 23.8 \\
\hline & $2085 s$ & 25.7 & 25.2 & 25.6 & 25.4 & 23.4 & 23.4 & 23.4 & 23.6 & 23.4 & 23.5 & 24.3 & 24.5 & 24.3 & 24.4 \\
\hline & Baseline & & & & .4 & & .5 & & .7 & & .6 & & & & \\
\hline & $2025 s$ & 20.7 & 20.4 & 20.6 & 20.5 & 18.8 & 18.7 & 18.8 & 18.9 & 18.8 & 18.7 & 19.7 & 19.6 & 19.7 & 19.6 \\
\hline Ар1 & $2055 s$ & 21.6 & 21.1 & 21.6 & 21.3 & 19.8 & 19.5 & 19.8 & 19.7 & 19.7 & 19.5 & 20.6 & 20.5 & 20.7 & 20.4 \\
\hline & $2085 s$ & 22.6 & 21.9 & 22.6 & 22.1 & 20.8 & 20.3 & 20.8 & 20.5 & 20.7 & 20.6 & 21.6 & 21.5 & 21.6 & 21.4 \\
\hline
\end{tabular}




\section{Continued}

\begin{tabular}{|c|c|c|c|c|c|c|c|c|c|c|c|c|c|c|c|}
\hline \multirow{4}{*}{ May } & Baseline & \multicolumn{2}{|c|}{16.5} & \multicolumn{2}{|c|}{16.5} & \multicolumn{2}{|c|}{15.2} & \multicolumn{2}{|c|}{15.4} & \multicolumn{2}{|c|}{15.2} & \multicolumn{2}{|c|}{16.0} & \multicolumn{2}{|c|}{16.0} \\
\hline & $2025 s$ & 17.8 & 17.6 & 17.8 & 17.7 & 16.5 & 16.5 & 16.5 & 16.7 & 16.5 & 16.5 & 17.3 & 17.3 & 17.3 & 17.2 \\
\hline & $2055 s$ & 18.7 & 18.7 & 18.6 & 18.8 & 17.3 & 17.6 & 17.3 & 17.7 & 17.2 & 17.6 & 18.1 & 18.4 & 18.1 & 18.3 \\
\hline & $2085 s$ & 19.5 & 19.1 & 19.5 & 19.3 & 18.2 & 18.1 & 18.2 & 18.3 & 18.1 & 18.3 & 18.9 & 19.1 & 18.9 & 18.9 \\
\hline \multirow{4}{*}{ Jun } & Baseline & \multicolumn{2}{|c|}{14.2} & \multicolumn{2}{|c|}{14.2} & \multicolumn{2}{|c|}{12.9} & \multicolumn{2}{|c|}{13.2} & \multicolumn{2}{|c|}{12.9} & \multicolumn{2}{|c|}{13.5} & \multicolumn{2}{|c|}{13.5} \\
\hline & $2025 s$ & 15.2 & 15.2 & 15.2 & 15.3 & 14.0 & 14.0 & 14.0 & 14.2 & 13.9 & 14.0 & 14.5 & 14.6 & 14.5 & 14.5 \\
\hline & $2055 s$ & 16.3 & 16.1 & 16.2 & 16.3 & 15.0 & 15.1 & 15.0 & 15.3 & 14.8 & 15.1 & 15.4 & 15.7 & 15.5 & 15.6 \\
\hline & $2085 s$ & 17.1 & 16.6 & 17.1 & 16.9 & 15.8 & 15.7 & 15.8 & 16.0 & 15.7 & 15.8 & 16.3 & 16.4 & 16.3 & 16.3 \\
\hline \multirow{4}{*}{ Jul } & Baseline & \multicolumn{2}{|c|}{14.6} & \multicolumn{2}{|c|}{14.6} & \multicolumn{2}{|c|}{13.3} & \multicolumn{2}{|c|}{13.6} & \multicolumn{2}{|c|}{13.3} & \multicolumn{2}{|c|}{13.6} & \multicolumn{2}{|c|}{13.6} \\
\hline & $2025 s$ & 15.7 & 15.8 & 15.6 & 15.9 & 14.3 & 14.6 & 14.3 & 14.9 & 14.3 & 14.7 & 14.6 & 15.0 & 14.6 & 14.9 \\
\hline & $2055 s$ & 16.7 & 16.9 & 16.6 & 17.1 & 15.3 & 15.8 & 15.3 & 16.1 & 15.2 & 15.9 & 15.5 & 16.2 & 15.6 & 16.1 \\
\hline & $2085 s$ & 17.6 & 17.6 & 17.5 & 17.9 & 16.2 & 16.5 & 16.2 & 16.8 & 16.1 & 16.8 & 16.4 & 17.1 & 16.4 & 17.0 \\
\hline \multirow{4}{*}{ Aug } & Baseline & & & & & & & & & & & & & & \\
\hline & $2025 s$ & 17.4 & 17.4 & 17.3 & 17.5 & 15.0 & 15.2 & 15.0 & 15.6 & 15.0 & 15.2 & 15.8 & 16.0 & 15.8 & 16.0 \\
\hline & $2055 s$ & 18.6 & 18.7 & 18.6 & 18.9 & 16.4 & 16.4 & 16.4 & 16.8 & 16.2 & 16.5 & 17.0 & 17.4 & 17.0 & 17.3 \\
\hline & $2085 s$ & 19.4 & 19.4 & 19.4 & 19.8 & 17.2 & 17.2 & 17.2 & 17.5 & 17.0 & 17.5 & 17.8 & 18.5 & 17.8 & 18.3 \\
\hline & Baseline & & & & & & & & & & & & & & \\
\hline & $2025 s$ & 18.4 & 18.7 & 18.4 & 18.9 & 16.6 & 17.2 & 16.6 & 17.3 & 16.6 & 17.1 & 17.2 & 17.8 & 17.2 & 17.7 \\
\hline & $2055 s$ & 19.6 & 20.0 & 19.6 & 20.3 & 17.9 & 18.5 & 17.9 & 18.6 & 17.8 & 18.5 & 18.4 & 19.2 & 18.4 & 19.1 \\
\hline & $2085 s$ & 20.5 & 20.6 & 20.4 & 20.9 & 18.7 & 19.1 & 18.7 & 19.3 & 18.6 & 19.4 & 19.2 & 20.0 & 19.2 & 19.9 \\
\hline & Baseline & & & & & & & & & & & & & & \\
\hline & $2025 s$ & 21.2 & 21.2 & 21.1 & 21.3 & 18.8 & 19.0 & 18.8 & 19.3 & 18.7 & 19.0 & 19.6 & 19.8 & 19.6 & 19.8 \\
\hline & $2055 s$ & 22.1 & 22.2 & 22.0 & 22.4 & 19.7 & 20.1 & 19.7 & 20.4 & 19.6 & 20.0 & 20.4 & 20.8 & 20.4 & 20.8 \\
\hline & $2085 s$ & 23.0 & 22.9 & 22.9 & 23.1 & 20.5 & 20.7 & 20.5 & 21.1 & 20.4 & 21.0 & 21.3 & 21.8 & 21.3 & 21.7 \\
\hline & Baseline & & & & & & & & & & & & & & \\
\hline & $2025 s$ & 23.6 & 23.5 & 23.5 & 23.6 & 20.6 & 20.7 & 20.6 & 20.9 & 20.5 & 20.7 & 21.7 & 21.9 & 21.7 & 21.9 \\
\hline & $2055 s$ & 24.7 & 24.2 & 24.7 & 24.4 & 21.7 & 21.5 & 21.7 & 21.7 & 21.6 & 21.5 & 22.9 & 22.7 & 22.9 & 22.6 \\
\hline & $2085 s$ & 25.5 & 24.9 & 25.4 & 25.1 & 22.5 & 22.2 & 22.5 & 22.4 & 22.4 & 22.4 & 23.6 & 23.6 & 23.6 & 23.5 \\
\hline & Baseline & & & & & & & & & & & & & & \\
\hline & $2025 s$ & 25.2 & 25.2 & 25.1 & 25.3 & 22.3 & 22.5 & 22.3 & 22.7 & 22.3 & 22.6 & 23.5 & 23.8 & 23.5 & 23.7 \\
\hline & $2055 s$ & 26.3 & 26.0 & 26.2 & 26.2 & 23.3 & 23.4 & 23.3 & 23.6 & 23.3 & 23.5 & 24.5 & 24.7 & 24.5 & 24.6 \\
\hline & 2085s & 26.9 & 26.5 & 26.8 & 26.8 & 23.9 & 24.1 & 23.9 & 24.2 & 23.8 & 24.2 & 25.0 & 25.5 & 25.1 & 25.3 \\
\hline
\end{tabular}

${ }^{\mathrm{a}} \mathrm{AVG}$ : monthly mean temperature averaged for GCMs projections; ${ }^{\mathrm{b}} \mathrm{AVR}$ : monthly mean temperature averaged for RCMs projections. 
In most cases, the results demonstrate that higher temperatures are projected by ETA model with its various projections. Only for April (all locations), higher temperatures were provided by the projections of GCMs. Moreover, higher temperatures are expected in locations 1, 2, 6 and 7 in the east and central portions of the region. December, January and February are the warmest months, while June and July are the coldest months, with amplitude of more than 10 degrees among these months. All projections indicate an increase in temperature in all locations, and it is possible that winters will become warmer compared to the summers. The anomalies in 2025s have lower fluctuations than for subsequent periods and it is expected that the major differences will be felt between 2025s and 2055s than between 2055s and 2085s.

The study conducted by [37] showed similar results on the analysis of average and minimum temperatures in southern Brazil during the 1960-2002 period. They are consistent with the trends provided by the projections used in this study. The authors point out to a warming in the southern region of the country with positive trends in maximum and minimum temperatures. They add also that warming will be more intense during the winter than in the summer, probably due to the greater number of warm days in the winter.

Regarding precipitation, GCMs agree with each other in different locations (lower variability). In some cases, however, they provide projections contrary to the ETA model. They also provide lower seasonal variability with respect to the baseline period. About this fact, it is observed that for the months of December, January and February, the GCMs indicate that there will be little or no change in comparison to 1961-1990. Hence, this entails that it is not expected changes during most of the months of the summer crop (November to March). Additionally, smaller increases in temperature for these months may indicate that the impacts are likely to be less severe. Regarding precipitation, GCMs agree with each other in different locations (lower variability). In some cases, however, they provide projections contrary to the ETA model. They also provide lower seasonal variability with respect to the baseline period. About this fact, it is observed that for the months of December, January and February, the GCMs indicate that there will be little or no change in comparison to 1961-1990. Hence, this entails that it is not expected changes during most of the months of the summer crop (November to March). Additionally, smaller increases in temperature for these months may indicate that the impacts are likely to be less severe.

Only the months of March, May and November had strictly positive anomalies for all future periods in all locations. The months of July, August and September had the largest reductions, and almost all anomalies were negative in August, generated by both GCMs and the projections of the ETA model. In these months, negative anomalies projected by ETA model were obtained only for the months of February and December in locations 1 and 6, respectively, in all future periods. The projections for August provided the highest reductions, reaching anomalies of up to $20 \mathrm{~mm}$.

Comparing the anomalies between AVG and AVR, it is observed that all anomalies calculated for the ETA model are much larger than those provided by GCMs. Hence, the regional climate model projects a situation that is more favorable associated to an increase in precipitation amounts. This increase, in general, is greater the further it gets from the baseline period for each month, except for the months of February, July and September, when we observe the largest increases in the middle of the century (2055s). The major positive anomalies were obtained for May and November, which are the months when the winter and summer crop are sown, respectively.

In general, it can be said that the models agree with each other that during the months of summer crop there will be an increase in precipitation, and it is possible that agriculture will not be negatively affected by this variable. With regard to the anomalies, it was found that the projections of positive anomalies have greater magnitude than the negative anomalies.

\subsection{Extreme Rainfall Indices}

To facilitate the visualization of the results, only the mean values of the selected indices for rainfall projections given by GCMs and the RCM projections (AVG and AVR, respectively) are presented in Table 7, for each location. However, the Mann-Kendall test was performed for each annual series of the indices considered in each location and for each model.

The first index, R95p, refers to the total rainfall of the days when precipitation is greater than the 95th percentile. Thus, if there is an increase trend of this index, this may indicate that the increase of precipitation discussed in the previous section is partly due to the occurrence of heavy rain (more concentrated in time). In all locations, this index was higher for GCMs than for the ETA model and is greater the further it gets from the baseline period (Table 7). However, the hypothesis test reveals increasing trends in all locations only for the ETA 20 model 
Table 7. Mean annual precipitation indices for all locations and time slices, based on averaged regional and global climate models.

\begin{tabular}{|c|c|c|c|c|c|c|c|c|c|c|c|c|c|c|c|c|c|}
\hline \multirow{3}{*}{ "ृี } & \multirow{3}{*}{ Period } & \multicolumn{16}{|c|}{ Models } \\
\hline & & \multicolumn{8}{|c|}{ AVR } & \multicolumn{8}{|c|}{ AVG } \\
\hline & & $\begin{array}{l}\text { R95p } \\
(\mathrm{mm})\end{array}$ & $\begin{array}{l}\text { R99p } \\
\text { (mm) }\end{array}$ & $\begin{array}{l}\text { PRCPTOT } \\
(\mathrm{mm})\end{array}$ & $\begin{array}{l}\text { R30 } \\
(\mathrm{mm})\end{array}$ & $\begin{array}{c}\mathrm{RX1} \\
\text { (days) }\end{array}$ & $\begin{array}{l}\text { RX5 } \\
\text { (days) }\end{array}$ & $\begin{array}{l}\text { CDD } \\
\text { (days) }\end{array}$ & $\begin{array}{l}\text { CWD } \\
\text { (days) }\end{array}$ & $\begin{array}{l}\text { R95p } \\
(\mathrm{mm})\end{array}$ & $\begin{array}{l}\text { R99p } \\
(\mathrm{mm})\end{array}$ & $\begin{array}{l}\text { PRCPTOT } \\
(\mathrm{mm})\end{array}$ & $\begin{array}{l}\mathrm{R} 30 \\
(\mathrm{~mm})\end{array}$ & $\begin{array}{c}\mathrm{RX1} \\
\text { (days) }\end{array}$ & $\begin{array}{l}\text { RX5 } \\
\text { (days) }\end{array}$ & $\begin{array}{l}\text { CDD } \\
\text { (days) }\end{array}$ & $\begin{array}{l}\text { CWD } \\
\text { (days) }\end{array}$ \\
\hline & Baseline & 786 & 269 & 1717 & 16 & 87 & 149 & 18 & 8 & 772 & 263 & 1717 & 16 & 86 & 144 & 17 & 8 \\
\hline \multirow{3}{*}{1} & $2025 s$ & 749 & 258 & 1829 & 17 & 89 & 161 & 24 & 8 & 790 & 273 & 1730 & 16 & 89 & 150 & 17 & 8 \\
\hline & 2055s & 791 & 272 & 1945 & 19 & 94 & 172 & 25 & 8 & 817 & 285 & 1781 & 16 & 93 & 158 & 17 & 8 \\
\hline & $2085 \mathrm{~s}$ & 822 & 279 & 2047 & 21 & 96 & 175 & 25 & 8 & 847 & 299 & 1836 & 17 & 99 & 165 & 17 & 8 \\
\hline \multirow[t]{4}{*}{ B } & Baseline & 811 & 271 & 1683 & 17 & 84 & 152 & 20 & 7 & 794 & 264 & 1683 & 17 & 82 & 152 & 20 & 7 \\
\hline & $2025 s$ & 788 & 264 & 1912 & 20 & 91 & 171 & 19 & 7 & 818 & 277 & 1710 & 18 & 86 & 159 & 19 & 7 \\
\hline & $2055 s$ & 825 & 270 & 2048 & 22 & 93 & 181 & 20 & 7 & 847 & 286 & 1765 & 18 & 89 & 165 & 19 & 7 \\
\hline & $2085 \mathrm{~s}$ & 868 & 282 & 2201 & 25 & 96 & 186 & 20 & 7 & 877 & 296 & 1815 & 19 & 92 & 170 & 19 & 7 \\
\hline \multirow[t]{4}{*}{ B } & Baseline & 866 & 305 & 1781 & 18 & 98 & 172 & 20 & 7 & 854 & 297 & 1781 & 18 & 94 & 169 & 21 & 7 \\
\hline & $2025 s$ & 816 & 272 & 2015 & 22 & 97 & 188 & 20 & 7 & 889 & 313 & 1830 & 19 & 101 & 179 & 21 & 7 \\
\hline & $2055 \mathrm{~s}$ & 874 & 288 & 2213 & 25 & 101 & 202 & 23 & 7 & 925 & 324 & 1904 & 20 & 104 & 186 & 21 & 7 \\
\hline & $2085 s$ & 908 & 298 & 2365 & 27 & 103 & 205 & 22 & 7 & 950 & 334 & 1944 & 20 & 108 & 192 & 21 & 7 \\
\hline \multirow{4}{*}{4} & Baseline & 791 & 271 & 1838 & 16 & 86 & 155 & 17 & 9 & 782 & 265 & 1838 & 16 & 84 & 155 & 16 & 10 \\
\hline & $2025 s$ & 786 & 263 & 2097 & 19 & 91 & 179 & 16 & 9 & 814 & 280 & 1881 & 16 & 90 & 165 & 16 & 10 \\
\hline & $2055 \mathrm{~s}$ & 847 & 279 & 2300 & 23 & 96 & 191 & 18 & 10 & 849 & 292 & 1958 & 18 & 94 & 172 & 16 & 10 \\
\hline & $2085 \mathrm{~s}$ & 885 & 288 & 2452 & 25 & 96 & 196 & 17 & 10 & 874 & 302 & 2001 & 18 & 97 & 178 & 16 & 10 \\
\hline \multirow[t]{4}{*}{ B } & Baseline & 750 & 250 & 1639 & 15 & 78 & 145 & 19 & 8 & 736 & 242 & 1639 & 15 & 73 & 147 & 19 & 8 \\
\hline & $2025 s$ & 743 & 245 & 1907 & 19 & 84 & 167 & 17 & 8 & 769 & 257 & 1693 & 16 & 78 & 156 & 20 & 8 \\
\hline & $2055 \mathrm{~s}$ & 791 & 261 & 2097 & 22 & 89 & 178 & 19 & 8 & 800 & 268 & 1757 & 17 & 81 & 162 & 19 & 8 \\
\hline & $2085 s$ & 820 & 265 & 2197 & 24 & 89 & 182 & 18 & 8 & 828 & 278 & 1799 & 18 & 85 & 169 & 20 & 8 \\
\hline \multirow[t]{4}{*}{ B } & Baseline & 775 & 262 & 1661 & 16 & 84 & 152 & 20 & 7 & 763 & 255 & 1661 & 16 & 84 & 150 & 20 & 7 \\
\hline & $2025 s$ & 750 & 253 & 1820 & 19 & 88 & 171 & 27 & 7 & 798 & 270 & 1712 & 17 & 89 & 160 & 21 & 7 \\
\hline & $2055 \mathrm{~s}$ & 791 & 264 & 1974 & 21 & 93 & 179 & 27 & 7 & 825 & 279 & 1770 & 18 & 92 & 166 & 20 & 7 \\
\hline & $2085 \mathrm{~s}$ & 829 & 274 & 2072 & 22 & 95 & 188 & 28 & 7 & 856 & 293 & 1816 & 19 & 99 & 174 & 20 & 7 \\
\hline \multirow{4}{*}{7} & Baseline & 745 & 261 & 1588 & 14 & 86 & 148 & 19 & 7 & 735 & 251 & 1588 & 14 & 83 & 148 & 19 & 7 \\
\hline & $2025 s$ & 749 & 262 & 1842 & 17 & 92 & 166 & 17 & 8 & 766 & 267 & 1633 & 15 & 88 & 157 & 19 & 7 \\
\hline & $2055 s$ & 799 & 276 & 1998 & 20 & 98 & 180 & 18 & 8 & 792 & 274 & 1685 & 16 & 90 & 162 & 19 & 7 \\
\hline & $2085 s$ & 833 & 283 & 2092 & 21 & 97 & 185 & 18 & 8 & 826 & 291 & 1739 & 16 & 97 & 171 & 19 & 7 \\
\hline
\end{tabular}

and any trend for HADCM3 and NRCCCSM models in any location. It was found that the locations 6 and 7 showed no trends by none of the models. This fact indicates a spatial distribution of impacts, suggesting that the climate near these locations is different from the rest of the region and will be less affected by a changing climate. Statistical evidence of trend was found for almost all regional projections, while for the global model only GFCM21 presented trend in all locations, except in location 7. 
Although average precipitation given by GCMs was higher, this result is not in contradiction with the hypothesis test, which demonstrated higher trends for the ETA model. This can be better understood in Figure 4 . This figure presents the trends that have been tested for ETA 20 and NRCCCSM models. Note that, although the NRCCCSM model has a higher average R95p index, its trend line is less steep than for ETA 20 model. Thus, the difference in average values refers only to variability among models, while the Mann-Kendall test identifies trends over time.

All locations showed increasing trends for at least 5 of the 10 climate models, except for the location 7. In this location, trend was detected only for the ETA 20 and ETA 40 HIGH models for the level of significance adopted in this study. The graphs also show the large interannual variability of this index.

The analysis of R99p index follows the same logic as above, but considers the sum of the days with even more intense rainfall, above the 99th percentile. However, trend for this index was detected for only few projections, and in any location that has happened for more than 3 climate models. The R95p and R99p indices also indicate how much of the total annual precipitation is probably to occur in more intense or extreme events. For example, the total rainfall in 2050 in location 1 for the ETA 40 CTRL model is $2596 \mathrm{~mm}$. Of this total, is expected that $532 \mathrm{~mm}$ (approximately 20\%) precipitate in rainy days with precipitation above 95th percentile and $213 \mathrm{~mm}$ (approximately 8\%) occur in days with precipitation above the 99th percentile. In agriculture, these may be the worst precipitation events, because the crops can be quickly destroyed. For models that registered positive trends may be due to either the occurrence of heavy rains or more frequent occurrence of these extreme rainfall events. To answer this question, the trend of the number of days necessary to generate a certain amount of precipitation should have been analyzed, but this is out of the scope of this work.

For the PRCPTOT index, which corresponds to the total annual precipitation of wet days ( $\mathrm{P} \geq 1 \mathrm{~mm})$, the highest values were provided by the ETA model and its members. Except for locations 1 and 6, the ETA model predicted up to $600 \mathrm{~mm}$ more than the baseline period for this index in 2085s. With respect to the GCMs, they suggested an increase in precipitation of $160 \mathrm{~mm}$ in the whole region for the same period. The Mann-Kendall test for this index detected an upward trend only for ETA model and rejects this assumption for all GCMs.

Similar results were obtained for R30 index (days), which counts the number of days in the year with precipitation greater than $30 \mathrm{~mm}$. This index also helps in the detection of extreme events, since they can be associated with the previous two indices. For example, the 95th percentile of ETA 20 in 2022 and 2033 (not shown) were $30 \mathrm{~mm}$, approximately. If we associate the indices R95p and R30, we may notice that in 2022, only 5 days (R30, in 2022) were responsible for a rain of $260 \mathrm{~mm}$ (R95p, 2022); and in 2033, 7 days (R30, in 2033) accounted for a rain of $360 \mathrm{~mm}$ (R95p, in 2033). Although this analysis is not presented here for all projections and locations, it is very useful to understand how many days are needed to generate a certain amount of precipitation.

For GCMs, it is noted from Table 7 that the R30 index has no changes with respect to the period 1961-1990, and it is at most 3 days more than in 2085s. However, the rates calculated for the regional projections reveal up to 9 days with precipitation greater than $30 \mathrm{~mm}$ in 2085s. In this case, only the ETA $40 \mathrm{HIGH}$ showed trend in locations 6 and 7 and any trend in location 5. In other locations, no more than 3 trends were detected for the other climate projections.

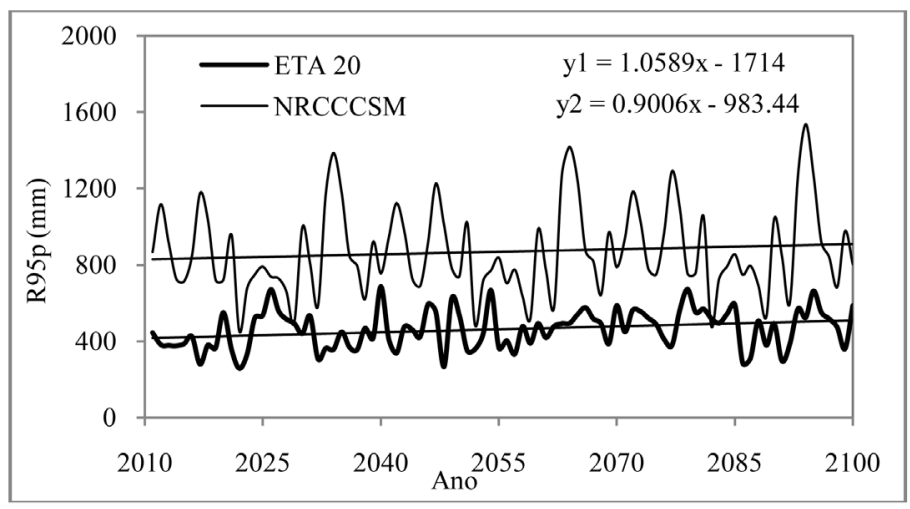

Figure 4. Differences among models and R95 index increasing trends (mm) for ETA 20 and NRCCCSM models, location 1 (y1 and y2 are trend lines for ETA 20 and NRCCCSM models, respectively). 
For all other indices, any trend was detected neither for ETA model, nor for the GCMs. Comparing the RX1 and RX5 indices, one may observe that the maximum precipitation in a day (RX1) is proportionately much more extreme than the total rainfall in five consecutive wet days (RX5). Although there is no upward trend, these average values are of concern because they represent days with very intense rainfall. Finally, CDD and CWD indices varied between 16 and 21 days and between 7 and 10 days, respectively. There is no statistical evidence of trend for these indices. Locations 1 and 4 provided lower consecutive dry days and higher consecutive wet days.

\section{Conclusions}

This study aimed to detect evidence of climate change in the northwest region of the State of Rio Grande do Sul, Brazil. This region is the third largest producer of soybean in the state, contributing significantly to the national productivity. Ten projections of general and regional circulation models were considered in seven different locations in the region. The analysis was carried out for the period from 2011 to 2100 and compared with the baseline period (1960-1990).

In most cases, both the ETA model and GCMs agreed about an increase in temperature and precipitation in all seven locations. Projections indicate an increase of mean annual temperature of almost $3^{\circ} \mathrm{C}$ till the end of the century, a little lower than found by other authors. Additionally, we expect that the locations 6 and 7 are likely to suffer with the highest average temperatures. Regarding annual cumulative precipitation, only for the location 6 is predicted a reduction in rainfall amounts. It can be concluded that it is possible that the climate in these locations (more severe towards the center of the state) is different from the rest of the region and that the spatial distribution of the impacts of climate change on agriculture will not be uniform.

The seasonal cycles of monthly temperature and precipitation show that the months of the summer crop will be the least affected by the increase in these variables. However, this fact does not mean that the changes in $\mathrm{T}$ and $\mathrm{P}$ are not significant. Regarding this fact, one may observe a great variability between the projections of ETA model and its members and the GCMs applied in this study. This can be confirmed by analyzing the trends in extreme precipitation indices, which showed that most of upward trends were detected for the indices provided by the regional model projections. Since RCMs are constructed for smaller areas with a higher resolution, their projections are believed to be closer to reality than global models. Thus, based on the abovementioned, it could be assumed that it is possible that future climate will be characterized by more frequent extreme events of precipitation in the northwest region.

Additionally, the results presented here are useful to demonstrate the influence of the downscaling on the results. Furthermore, the average precipitations projected by the GCMs were higher than for the ETA model, but increasing trends were not detected for most indices calculated from global projections.

Furthermore, the differences between the results found in this study and the others mentioned in this paper are in part due to different greenhouse gas emission scenarios considered. Therefore, our results are based on projections for a scenario (A1B) which is not as pessimistic as A2. For example, the work presented by [19] indicates temperature increases up to $5.5^{\circ} \mathrm{C}$ in 2085 s for $\mathrm{A} 2$ scenario.

Since there is no other research applying regional climate models for the northwest region of Rio Grande do Sul, we believe that this study contributed to improving the findings on climate change for the south of Brazil. Even if indirectly, this work also helps demonstrate that, for the same model, there is a great variability. This variability increases the uncertainty about the conclusions and exposes the difficulty in understanding the extent to which climate change may manifest in a particular location.

\section{Acknowledgements}

We are very thankful to the National Council of Scientific and Technological Development (CNPq) for sponsoring this research and acknowledge all anonymous reviewers for their suggestions and improvements in this paper.

\section{References}

[1] Yoo, S.H., Choi, J.Y., Nam, W.H. and Hong, E. (2012) Analysis of Design Water Requirement of Paddy Rice Using Frequency Analysis Affected by Climate Change in South Korea. Agricultural Water Management, 112, 33-42. http://dx.doi.org/10.1016/j.agwat.2012.06.002

[2] World Bank (2009) World Development Report 2010: Development and Climate Change. World Bank, Washington 
DC.

[3] Barry, R.G. and Chorley, R.J. (2009) Atmosphere, Weather and Climate. 9th Edition, Routledge, New York.

[4] Marengo, J.A. and Soares, W. (2003) Clima e Recursos Hídricos 9. ABRH/FBMC-ANA, Porto Alegre.

[5] Nkomozepi, T. and Chung, S.O. (2012) Assessing the Trends and Uncertainty of Maize Net Irrigation Water Requirement Estimated from Climate Change Projections for Zimbabwe. Agricultural Water Management, 111, 60-67. http://dx.doi.org/10.1016/j.agwat.2012.05.004

[6] Alexander, L.V., Zhang, X., Peterson, T.C., Caesar, J., Bleason, B., Klein Tank, A.M.G., Haylock, M., Collins, D., Trewin, B., Rahimzadeh, F., Tagipour, A., Rupa Kumar, K., Revadekar, J., Griffiths, G., Vincent, L., Stephenson, D.B., Burn, J., Aguilar, E., Brunet, M., Taylor, M., New, M., Zhai, P., Rusticucci, M. and Vazquez-Aguirre, J.L. (2006) Global Observed Changes in Daily Climate Extremes of Temperature and Precipitation. Journal of Geophysical Research, 111, 1-22. http://dx.doi.org/10.1029/2005JD006290

[7] Kiktev, D., Sexton, D.M.H., Alexander, L. and Folland, C.K. (2003) Comparison of Modeled and Observed Trends in Indices of Daily Climate Extremes. Journal of Climate, 16, 3560-3571. http://dx.doi.org/10.1175/1520-0442(2003)016<3560:COMAOT>2.0.CO;2

[8] Marengo, J.A., Ambrizzi, T., Rocha, R.P., Alves, L.M., Cuadra, S.V., Valverde, M.C., Torres, R.R., Santos, D.C. and Ferraz, S.E.T. (2010) Future Change of Climate in South America in the Late Twenty-First Century: Intercomparison of Scenarios from Three Regional Climate Models. Climate Dynamics, 35, 1073-1097. http://dx.doi.org/10.1007/s00382-009-0721-6

[9] Vincent, L.A., Peterson, R.C., Barros, V.R., Marino, M.B., Rusticucci, M., Carrasco, G., Ramirez, E., Ambrizzi, T., Berlato, M.A., Grimm, A.M., Marengo, J.A., Molion, L., Moncunill, D.F., Rebello, E., Anunciação, Y.M.T., Quintana, J., Santos, J.L., Baez, J., Coronel, G., Garcia, J., Trebejo, I., Bidegain, M., Haylock, M.R. and Karoly, D. (2005) Observed Trends in Indices of Daily Temperature Extremes in South America 1960-2000. Bulletin of the American Meteorological Society, 18, 5011-5023. http://dx.doi.org/10.1175/JCLI3589.1

[10] Nogués-Paegle, J. and Mo, K. (1997) Alternating Wet and Dry Conditions over South America during Summer. Bulletin of the American Meteorological Society, 125, 279-291. http://dx.doi.org/10.1175/1520-0493(1997)125<0279:AWADCO>2.0.CO;2

[11] Brito, A.L., Veiga, J.A.P. and Yoshida, M.C. (2014) Extreme Rainfall Events over the Amazon Basin Produce Significant Quantities of Rain Relative to the Rainfall Climatology. Atmospheric and Climate Sciences, 4, 179-191. http://dx.doi.org/10.4236/acs.2014.42021

[12] Souza, E.B., Moraes, B.C., Ferreira, D.B.S. and Meira-Filho, L.G. (2014) Dynamical Downscaling for Railroad Areas in Eastern Amazon and Southeastern Brazil: Current Climate and Near-Future Projections. Atmospheric and Climate Sciences, 4, 155-163. http://dx.doi.org/10.4236/acs.2014.42018

[13] Valverde, M.C. and Marengo, J.A. (2014) Extreme Rainfall Indices in the Hydrographic Basins of Brazil. Open Journal of Modern Hydrology, 4, 10-26. http://dx.doi.org/10.4236/ojmh.2014.41002

[14] Dereczynski, C., Silva, W.L. and Marengo, J.A. (2013) Detection and Projections of Climate Change in Rio de Janeiro, Brazil. American Journal of Climate Change, 2, 25-33. http://dx.doi.org/10.4236/ajcc.2013.21003

[15] Machado, R.D. and Rocha, R.P. (2011) Previsões climáticas sazonais sobre o Brasil: Avaliação do REGCM3 aninhado no modelo global CPTEC/COLA. Revista Brasileira de Meteorologia, 26, 121-136.

[16] Marengo, J.A. and Valverde, M.C. (2007) Caracterização do clima no Século XX e Cenário de Mudanças de clima para o Brasil no Século XXI usando os modelos do IPCC-AR4. Revista Multiciência, 8, 5-27.

[17] Grimm, A.M. (2003) The El Ni-o Impact on the Summer Monsoon in Brazil: Regional Processes versus Remote Influences. Bulletin of the American Meteorological Society, 16, 263-280.

[18] Grimm, A.M., Ferraz, S.E.T. and Gomes, J. (1998) Precipitation Anomalies in Southern Brazil Associated with El Ni-o and La Ni-a Events. Bulletin of the American Meteorological Society, 11, 2863-2880.

[19] Hamada, E., Gonçalves, R.R.V., Orsini, J.A.M. and Ghini, R. (2008) Future climate scenarios for Brazil. In: Ghini, R. and Hamada, E., Eds., Mudanças Climáticas: Impactos sobre doenças de plantas no Brasil, EMBRAPA Informação Tecnológica, Brasília-DF.

[20] Bates, B.C., Kundzewicz, Z.W., Wu, S. and Palutikof, J.P. (2008) Climate Change and Water Technical Paper of the Intergovernmental Panel on climate Change. IPCC Secretariat, Geneva.

[21] Marengo, J.A., Alves, L., Valverde, M., Rocha, R. and Laborbe, R. (2007) Eventos extremos em cenários regionalizados de clima no Brasil e América do Sul para o Século XXI: Projeções de clima futuro usando três modelos regionais. Relatório 5, Ministério do Meio Ambiente-MMA, Brasília.

[22] Justino, F., Oliveira, E.C., Rodrigues, R.A., Gonçalves, P.H.L., Souza, P.J.O.P., Stordal, F., Marengo, J.A., Silva, T.G., Delgado, R.C., Lindemann, D.S. and Costa, L.C. (2013) Mean and Interannual Variability of Maize and Soybean in 
Brazil under Global Warming Conditions. American Journal of Climate Change, 2, 237-253. http://dx.doi.org/10.4236/ajcc.2013.24024

[23] Bocchiola, D., Nana, E. and Soncini, A. (2013) Impact of Climate Change Scenarios on Crop Yield and Water Footprint of Maize in the Po Valley of Italy. Agricultural Water Management, 116, 50-61. http://dx.doi.org/10.1016/j.agwat.2012.10.009

[24] Hwan, Y.S., Yong, C.J., Hyun, L.S., Gyeong, O.Y. and Koun, Y.D. (2013) Climate Change Impacts on Water Storage Requirements of an Agricultural Reservoir Considering Changes in Land Use and Rice Growing Season in Korea. Agricultural Water Management, 117, 43-54. http://dx.doi.org/10.1016/j.agwat.2012.10.023

[25] Jalota, S.K., Kaur, H., Kaur, S. and Vashisht, B.B. (2013) Impact of Climate Change Scenarios on Yield, Water and Nitrogen-Balance and Use Efficiency of Rice-Wheat Cropping System. Agricultural Water Management, 116, $29-38$. http://dx.doi.org/10.1016/j.agwat.2012.10.010

[26] Harmsen, E.W., Niller, N.L., Schlegel, N.J. and Gonzalez, J.E. (2009) Seasonal Climate Change Impacts on Evapotranspiration, Precipitation Deficit and Crop Yield in Puerto Rico. Agricultural Water Management, 96, 1085-1095. http://dx.doi.org/10.1016/j.agwat.2009.02.006

[27] Marengo, J.A., Schaeffer, R., Pinto, H.S. and Zee, D.M.W. (2009) Mudanças climáticas e eventos extremos no Brasil. FBDS, Rio de Janeiro.

[28] Nedel, A., Sausen, T. and Saito, S. (2010) Zoneamento dos desastres naturais ocorridos no estado do Rio Grande do Sul no período 2003-2009-Parte I: Seca. Proceedings of the XVI Congresso Brasileiro de Meteorologia, Belém, 1317 Setembro 2010, 1-5.

[29] Fochezzato, A. and Grando, M.Z. (2009) Efeitos da estiagem na economia do Rio Grande do Sul: Uma abordagem multissetorial. Textos para Discussão FEE No. 62. Secretaria do Planejamento e Gestão Fundação de Economia e Estatística Siegfried Emanuel Heuser, Porto Alegre.

[30] Parry, M.L., Canziani, O.F., Palutikof, P.J., van der Linden, P.J. and Hanson, C.E., Eds. (2007) Climate Change 2007: Impacts, Adaptation and Vulnerability. Contribution of Working Group II to the Fourth Assessment Report of the Intergovernmental Panel on Climate Change, 2007. Cambridge University Press, Cambridge, UK and New York.

[31] Mesinger, F. and Janjic, Z.I. (1974) Noise Due to Time-Dependent Boundary Conditions in Limited Area Models. The GARP Programme on Numerical Experimentation, Report No. 4, WMO, Geneva.

[32] Black, T.L. (1994) The New NMC Mesoscale Eta Model: Description and Forecast Examples. Weather Forecasting, 9, 265-278.

[33] Solomon, S., Qin, D., Manning, M., Chen, Z., Marquis, M., Averyt, K.B., Tignor, M. and Miller, H.K. (2007) Climate Change 2007: The Physical Science Basis. Cambridge University Press, Cambridge. http://dx.doi.org/10.1175/1520-0434(1994)009<0265:TNNMEM>2.0.CO;2

[34] Mann, H.B. (1945) Non-Parametric Test against Trend. Econometrica, 13, 245-259. http://dx.doi.org/10.2307/1907187

[35] Kendall, M.G. (1975) Rank Correlation Methods. 4th Edition, Charles Griffin, London.

[36] Gilbert, R.O. (1987) Statistical Methods for Environmental Pollution Monitoring. Wiley, New York.

[37] Marengo, J.A. and Camargo, C. (2007) Surface Air Temperature Trends in Southern Brazil for 1960-2002. International Journal of Climatology, 11, 1-2. 